\section{Occurrence of Farnesene in the Natural Coating of Apples}

Previous investigation of the cuticle oil of the 'Granny Smith' apple in this Laboratory indicated the presence of small amounts of a hydrocarbon with a conjugated diene absorption in the ultra-violet. In view of its possible connexion with the serious storage disorder "superficial scald' it was isolated, and it has now been identified as the sesquiterpene farnesene (2,6-dimethyl-10-methylene-2,6, 11-dodecatriene) $)^{1,2}$.

'Granny Smith' apples (700 kg), stored at $1^{\circ} \mathrm{C}$ for six months, were washed with cold ethyl ether. The recovered coating (ursolic acid, cuticle wax and oil), freed of ether, was extracted with cold light petroleum (b.pt. below $40^{\circ} \mathrm{C}$ ), and the extract after concentration was treated with urea and methanol. The oily material not adducted by urea was chromatographed on 'Florisil'. Infra-red spectra of the material in the fractions eluted by light petroleum indicated a small saturated hydrocarbon fraction $(80 \mathrm{mg}$ ) followed by fractions $(750 \mathrm{mg})$ all showing the presence of unsaturated hydrocarbon. Gras chromatography on silicono and polyester columns of the unsaturated material showed one predominant peak and the compound responsible was recovered in a pure state from the silicono column. It has been positively identified as natural farnesene on the basis of the following evidence: $(a)$ its mass spectrum showed a molecular ion of $m / e=204 ;(b)$ its infra-rod spectrum was idontical with that published for pure natural farnesene $\mathrm{e}^{3}$; (c) hydrogenation on platinum in glacial acetic acid yielded farnesene $(2,6,10$-trimethyldodecane $)^{1}$, identified by its published infra-red spectrum ${ }^{2}$ as well as by direct comparison of its infra-red and mass spectra and gas chromatographic retention times on the above columns with those of an authentic specimen prepared from pure farmesol ${ }^{1}$.

Farnesene in the isolated fractions was observed to polymerize rapidly at room temperature in the presence of air, whereas it is stable in the whole extracted apple coating for about a year. Its labile nature and the fact that it constitutes at least 1 per cent of the 'Granny Smith' cuticle oil fraction has suggested to us that it may have a role in the development of superficial scald. Work is in progress to examine this hypothesis.

\section{K. E. Murray \\ F. E. HuELIN \\ J. B. DAVENPORT}

C.S.I.R.O.

Division of Food Preservation,

North Ryde, New South Wales, Australia.

\section{Sorm, F., Mleziva, J., Arnold, Z., and Pliva, J., Coll. Czech. Chem. Comm. 14, 899 (1949). \\ 'Sorm, F., and Arient, J., Coll. Czech. Chem. Comm., 15, 175 (1950). \\ ${ }^{3}$ Sorm, F., Zaoral, M., and Herout, V., Coll. Czech. Chem. Comm., 16, 626 (1951). \\ Ubiquinone-40 and Vitamin $K_{2}(40)$ in Chromatium vinosum}

Chromatium, an obligate photosynthetic anaerobe belonging to the purple sulphur bacteria (Thiorhodaceae), has been examined by several workers for the presence of lipophilic quinones. Thus, Chromatium, strain $D$, contains ubiquinone-35 (UQ ${ }_{7} ; 2.7 \mu \mathrm{M} / \mathrm{g}$, dry wt.) and a vitamin $K$ (refs. 1 and 2); both these quinones were found in the chromatophores ${ }^{2}$. Chromatium 8379 was reported as having largo amounts of ubiquinone-50 $\left(\mathrm{UQ}_{10}\right)$ and a vitamin $\mathrm{K}_{2}$ (ref. 3). Recently we have had the opportunity of examining $C$. vinosum for the presence of ubiquinone and vitamin $\mathbf{K}$ and have established the chain-length of the quinones present.

$C$. vinosum used was obtained from Lake Beloye (near Moscow), and shown to be photoautotrophic, requiring only carbon dioxide and hydrogen sulphide for growth 4 . It was grown on the following medium (g/l. distilled water): $\mathrm{NH}_{4} \mathrm{Cl}, 1 ; \mathrm{K}_{2} \mathrm{HPO}_{4}, 0 \cdot 5 ; \mathrm{MgCl}_{2}, 0 \cdot 2$; $\mathrm{NaCl}, 5 ; \mathrm{Na}_{2} \mathrm{~S} 9 \mathrm{H}_{2} \mathrm{O}, 2 ; \mathrm{NaHCO}_{3}, 5(p \mathrm{H} 7 \cdot 8-7 \cdot 9)$. The medium was dispensed in $250 \mathrm{ml}$. stoppered 'Pyrex' bottles, inoculated from a previous liquid culture, and grown anaerobically at $28^{\circ}$ with constant illumination from tungsten lamps.

After 7 days the cells were collected by high-speed centrifugation $(2,230 \mathrm{ml}$. media $\equiv 204 \mathrm{mg}$ dry wt. of cells) and the wet cell mass extracted twice with hot methanol (75 ml.) followed once by a hot ether-methanol mixture $(3: 1, \mathrm{v} / \mathrm{v} ; 75 \mathrm{ml}$.) The methanolic extracts were separated from the cell debris by centrifugation, the supernatants decanted into a separating funnel and the ether washed free from methanol with distilled wator. The ethereal layer was dried over anhydrous sodium sulphate (l h), filtered and taken to dryness under a stream of nitrogen. This yielded $64.3 \mathrm{mg}$ of a dark red oil.

The lipid extract was chromatographed on $10 \mathrm{~g}$ Brockmann grade III acid-washed alumina ('Woelm'); 100 ml. fractions of light petroleum $\left(40^{\circ}-60^{\circ}\right)$ containing increasing amounts $(0.25,1,3,5,8,12$ and 20 cer cent) of ether (peroxide free) were collected. Tho 1 per cont ether light petroleum fraction eluted $1 \cdot 1 \mathrm{mg}$ of a pale yellow oil with selective absorption bands in the ultra-violet region at $\lambda_{\max } 243,249,251$ and $260\left(E_{1}^{1 \%} 120,122\right.$, 111 and 106) in cyclohexane characteristic of the vitamins K. The 5 per cent ether-light petroleum fraction eluted $1.5 \mathrm{mg}$ of an orange-brown oil having a single absorption band at $\lambda_{\max } 275 \mathrm{~m} \mu\left(E_{1 \mathrm{~cm}}{ }^{1 \%} 77\right)$ in ethanol; on treatment of this fraction with $\mathrm{NaBH}_{4}$ the absorption at $275 \mathrm{m \mu}$ declined and a new peak appeared at $\lambda_{\max } 290 \mathrm{~m} \mu$; these changes are attributable to the presence of ubiquinone. In agreement with work carried out on Chromatium 8379 (ref. 3), tocopherols were not detected in any of the fractions. The levels of ubiquinone (from the spectroscopic changes on treatment with $\mathrm{NaBH}_{4}$ using $\lambda_{\max } 275$ $m \mu\left(\varepsilon_{\text {oxid }}-\varepsilon_{\text {red }}\right)=12,250$ ) and vitamin $K$ (using $\lambda_{\max }$ $249 \mathrm{~m} \mu \varepsilon=19,000$ ) in the fractions were estimated and the concentration per unit weight of cell material calculated as $2.5 \mu \mathrm{M}$ UQ/g dry wt. and $3-3.5 \mu \mathrm{M}$ vitamin $\mathrm{K} / \mathrm{g}$ dry wt. Since the estimation of vitamin $\mathrm{K}$ in the original fraction was difficult owing to irrelevant end absorption, a higher value was obtained on the crude fraction and a lower one was obtained after further purification by thin-layer chromatography (see below).

In order to characterize the quinones the fractions were purified further by quantitative thin-layer chromatography on 'Kieselgol $G$ ' plates impregnated with rhodamine $6 G$. The plates were developed in a saturation chamber ${ }^{5}$ with benzene-chloroform $(1: 1, \mathrm{v} / \mathrm{v})$ as developing solvent (vitamin $\mathrm{K} R_{F}=0 \cdot 68$, UQ $R_{F}=0 \cdot 3$ ). After development the quinones, visible as dark bands in daylight (under ultra-violet light the bands are more intense), were scraped off into ether and filtered to remove the gel and rhodamine. The recovered quinones had ultra-violet spectra qualitatively identical to those of vitamin $K$ and ubiquinone.

The ubiquinone recovered from thin-layer chromatograms was then chromatographed against standards in two ascending reversed-phase systems which allow the separation of the various homologues ${ }^{6, ?}$. The quinones were visualized by spraying with leucomethylene blue? In both systems the ubiquinone behaved as the -40 homologue $\left(\mathrm{UQ}_{8}\right)$.

The vitamin $\mathrm{K}$ sample, from its behaviour on thin-layer absorption chromatograms, was assigned to the $\mathbf{K}_{2}$ series. since in the systom described above it was resolved from vitamin $K_{1}$ and run with the vitamins $K_{2}$ (45) and (40). Accordingly, the sample was chromatographed against vitamin $\mathbf{K}_{2}$ standards in two reversed phase systems ${ }^{8,9}$ which will resolve the various isoprenologues. In both cases the menaquinone ran with and was not separated from vitamin $K_{2}(40)$. Additional evidence os to the 